\title{
Contextual factors associated with smoking among Brazilian adolescents
}

\author{
Sandhi Maria Barreto, ${ }^{1}$ Luana Giatti, ${ }^{1}$ Leticia Casado, ${ }^{2}$ Lenildo de Moura, ${ }^{3}$ \\ Claudio Crespo, ${ }^{4}$ Deborah Malta ${ }^{3,5}$
}

${ }^{1}$ Faculty of Medicine, Universidade Federal de Minas Gerais, Belo Horizonte-MG, Brazil

${ }^{2}$ National Institute of Cancer, Rio de Janeiro, RJ, Brazil ${ }^{3}$ Brazilian Ministry of Health, Health Surveillance Secretary, Non Communicable Diseases Coordination, Brasília-DF, Brazil ${ }^{4}$ National Institute of Geography and Statistics, Rio de Janeiro, RJ, Brazil

${ }^{5}$ Nursing School, University Federal de Minas Gerais, Belo Horizonte-MG, Brazi

\section{Correspondence to}

Professor Sandhi Maria Barreto, Faculty of Medicine, Universidade Federal de Minas Gerais, Av Alfredo Balena 190, sl 814, Belo Horizonte, CEP 30130100, Minas Gerais, Brazil; barreto@medicina.ufmg.br

Accepted 10 March 2011 Published Online First 6 April 2011

\section{ABSTRACT}

Background Very few studies have examined the role of school, household and family contexts in youth smoking in middle-income countries.

Methods This work describes smoking exposure among 59992 high school students who took part in the Brazilian Survey of School Health and investigates contextual factors associated with regular smoking, defined as smoking cigarettes at least once in the past 30 days. The explaining variables were grouped into: socio-demographic characteristics, school context, household context and family rapport. Variables independently associated with smoking in each context were identified by multiple logistic regression analysis.

Results $53 \%$ of the total sample were girls, $89 \%$ were aged $13-15$ years. $24 \%$ had already experimented with cigarettes, $50 \%$ before the age of 12 years. The prevalence of regular smoking was $6.3 \%(95 \% \mathrm{Cl} 5.87$ to 6.74), with no sex variation. Smoking was not associated with either the mother's education or the index of household assets. In the multivariable analysis, studying at a private school, the possibility of purchasing cigarettes at school and skipping of classes without parents' consent increased the chances of smoking. In the household context, living with both parents was negatively associated with smoking, while having smoking parents and exposure to other people's smoking was positively related to smoking. In the family context, parental unawareness of what the adolescent was doing increased smoking, but having meals with the mother one or more days per week and parents' negative reactions to adolescent smoking reduced the chances of smoking.

Conclusion The results reinforce the role of school, household and family contexts in youth smoking behaviours and will help improve public health policies aimed at preventing smoking and health promotion in adolescents.

\section{INTRODUCTION}

The exposure to smoking during adolescence has various important implications on the well-being and health of the adolescent, both cross-sectional and longitudinal. ${ }^{1}$ A cohort study in the USA has shown that half of the students who have experimented with tobacco smoke on a daily basis 1 year later. $^{2}$ The nicotine addiction can also start in adolescence and is not dependent on the daily use of tobacco. Longitudinal data collected annually from 1246 schools (2002-2006) found that the irregular use of cigarettes (not daily) can trigger nicotine addiction. Symptoms of premature addiction accelerate the frequency of tobacco use, and those who smoke more often tend to show more symptoms of addiction. ${ }^{3}$ In general, the survey results in this field have shown that out of five adolescents who use cigarettes, one to three are addicted to nicotine. ${ }^{4}$

Besides causing problems during adolescence, the use of tobacco in adolescence is also associated with use during adulthood. ${ }^{5}$ Peto et al have shown that the risk of lung cancer among individuals who started smoking before the age of 15 years is twice that of those who started at the age of 20 years or above. $^{6}$ Life-course analysis shows that adverse circumstances during childhood, including smoking, are associated with a worse self-assessment in terms of health in adulthood. ${ }^{7}$ Furthermore, a Finnish survey has shown that health-related risk behaviours during adolescence predict lower educational level in adulthood, contributing to an increase in health inequalities. 8

The use of tobacco during adolescence is, for the most part, culturally determined. There are various theoretical models to explain how social relations affect the initiation of risk behaviours such as smoking. ${ }^{9}$ A simpler ecological model of development during young age theorises that there is a complex interaction between individual and contextual factors, including the influence of the community, peers, school, family, society and media in general. ${ }^{10}$ Several empirical evidences sustain this contextual approach. The legal reinforcement which prohibits selling cigarettes to minors seems to have contributed to the reduction of $47 \%$ of the prevalence of daily smokers among youngsters in the USA between 1997 and 2003. ${ }^{11}$ Students who have schoolmates and/or parents who smoke are more likely to smoke themselves. ${ }^{12}$ The analyses of trends in school surveys have shown that the exposure to pro-tobacco commercials and smoking at home are positively associated with both the initiation and the maintenance of a smoking habit. ${ }^{13}$

The present work seeks to describe the exposure to smoking and to identify contextual factors in the school, household and family environments associated with regular smoking among Brazilian high school students who took part in a large, countrywide, school-based health survey.

\section{MATERIAL AND METHODS}

The National Adolescent School-based Health Survey (PeNSE), a cross-sectional study, was carried out by the Brazilian Ministry of Health among high school students in the 9th grade of public and private high schools in 26 capitals of the Brazilian states and in the Federal District during the months 
of May and June 2009. Among the 60973 high school students who participated in the survey, 981 were excluded from the present study because they did not respond to the question about cigarette use in the past 30 days. Of the 59992 high school students studied, $52.6 \%$ were girls, $0.7 \%$ were up to 12 years old, $23.7 \%$ were 13 years old, $47.1 \%$ were 14 years, $18.2 \%$ were 15 years old and $10.2 \%$ were 16 years or older.

In each city, private and public schools were defined as two strata and the final sample was proportional to the size of the stratum in each municipality. Within each stratum, a cluster sampling was used where the primary sampling unit was the school. Within the school one or two classes from the 9 th grade were randomly selected depending on the school size. All pupils in the randomly selected class were invited to participate.

The survey used questionnaires structured for self-application given in the classrooms and filled out by the students on a palmtop computer, the Personal Digital Assistant (PDA). The questionnaire had modules about several aspects of the life of the high school students: socio-demographic characteristics, diet patterns, body image, physical activities, smoking, consumption of alcohol and other drugs, oral health, sexual behaviour, exposure to violence and accidents, students' perception about family and general appreciation of the questionnaire.

The student's participation was voluntary, with the possibility of no responses to either a few questions or the whole questionnaire. The information obtained and the identity of the school were confidential and unidentifiable. The methodology of the survey has been described by Malta et al. ${ }^{14}$

\section{Variables}

In the present survey, the following items have been used to describe the exposure to smoking: experimentation with cigarettes at some point in life ('Have you ever smoked a cigarette, even if you just inhaled once or twice?'); the age of experimentation ('How old were you when you tried a cigarette for the first time?'); the regular smoking habit ('During the past 30 days, how many days have you smoked cigarettes?'). Considering this last question, students who reported having smoked cigarettes one or more days in the past 30 days were classified as regular smokers.

The magnitude of the associations between individual and contextual factors and regular smoking was determined by the OR and its $95 \%$ CIs was obtained by multiple logistic regression. The explaining variables were grouped into four domains according to the thematic affinity of the co-variables, described as follows:

1. Socio-demographic characteristics of the high school adolescent: sex (male and female), age in years, ethnic group/colour (white, black, brown, yellow, indigenous), educational level of the mother (graduate, incomplete undergraduate/complete middle school, incomplete middle school/complete primary education, incomplete primary education, no schooling, not informed) and parental socio-economic status. The last factor was measured by an index of household assets, which varied from 0 to 1 and was grouped in tertiles. To calculate the index, all goods with a prevalence of less than $70 \%$ in the sample (home telephone, washing machine, computer with internet connection, car and motorcycle) were taken into consideration, and the weight of each one was defined as $100 \%$ minus the relative frequency (\%) of the asset in the studied sample. Therefore, assets which were less common received a higher weight. ${ }^{15}$

2. Contextual characteristics of school: administrative domain (public or private), perception of access to cigarette sale inside the school (yes, no, not aware), reports of having skipped classes without parental permission in the past 30 days (never, 1 or 2 days, 3 or more days) and reports of bullying in school ('How often has any of your schoolmates made fun of you, joked around, bashed, intimidated or mocked you in such degree that you felt hurt, annoyed, angry, offended, humiliated?': never, rarely/occasionally, most of the time/always).

3. Household context: family composition (resides with father and mother, only with mother, only with father, doesn't reside with either father or mother), smoking habits of parents or responsible adults (none of them smoke, at least one smokes, both smoke) and number of days in which another person smoked at home in the past 7 days (none, 1-2 days, 3-6 days, every day).

4. Family rapport: has meals with mother or equivalent (every day, at least once a week, rarely, never), parents knew what the child was doing in the past 30 days (always/most of the time, sometimes/rarely, never) and perception of the parents' reaction if they knew that their child was smoking cigarettes (would care a lot, would care little, wouldn't care, don't know).

The research project was registered and approved by the Brazilian Committee of Research Ethics.

\section{Analysis}

When cluster sampling is employed, students' responses cannot be assumed to be independent, because school children within the same class are more likely to be similar to each other. A factor was used in the analysis to correct the design effect caused by the complex sampling procedure adopted, given that cluster sampling produces standard errors that tend to be higher than equivalent sample sizes obtained from random sampling. The design factor was defined as the ratio between the SE derived from a complex survey and that obtained by assuming a simple random sample. The analysis was carried out with Stata software (version 11.0) using the 'svy' procedure (with weighting factors) appropriate for the analysis of data obtained from complex sampling design. This procedure allows using different weights in the proportional estimation to correct for the different selection probabilities of each school.

The description of the variables experimentation with cigarettes at least once in life and regular smoking are presented by sex and age, and the age of experimentation by sex.

The associations between the independent explanatory variables and regular smoking were measured by Pearson's $\chi^{2}$ test with a significance level of 0.05 . The magnitude of the associations was measured by the ORs and its 95\% CIs obtained by multiple logistic regression. A multivariate analysis was carried out to identify the variables independently associated with regular smoking in each context analysed, after considering the effect of age and all the co-variables in the same context. The multivariate analysis included all variables related to smoking at a level of $\mathrm{p}<0.20$ in the univariate analysis.

\section{RESULTS}

Nearly one-fourth (24.17\%; 95\% CI $23.29 \%$ to $25.05 \%$ ) of the students reported having experimented with cigarettes at least once in life. The prevalence of students who had experimented with cigarettes increased with age, from $16.15 \%$ (95\% CI $15.03 \%$ to $17.34 \%$ ) among students aged 13 years or less to $41.30 \%(95 \%$ CI $39.50 \%$ to $43.11 \%$ ) among those who were 16 years or older, with no difference between sexes. The overall prevalence of 
regular smokers was $6.31 \%(95 \%$ CI 5.87 to 6.74$)$, which also increased with age, reaching $14.36 \%$ (95\% CI 12.86 to 16.00 ) among those who were 16 years or older, with no variation between boys and girls. Among those who had smoked cigarettes at least once in their lives, $49.30 \%$ (95 CI $47.67 \%$ to $50.93 \%$ ) had done so by the age of 12 , with boys experimenting at an earlier age than girls $(50.0 \%$ vs $48.67 \%, \mathrm{p}=0.0012)$.

Table 1 shows the results of the univariate analysis in each studied context. Regarding the socio-demographic characteristics, the prevalence of regular smoking differs significantly according to student age and educational level of the mother.

Concerning the school context, there was a difference in relation to the administrative domain of the school, to the reported absence in class without parental permission and to the perception of the possibility of purchasing cigarettes in school. There was no significant association between bullying and the prevalence of regular smoking $(p=0.962)$.

Regarding the domestic context, living with none or only one of the parents, having parents or responsible adults who smoke and having been exposed to smoking at home were all associated with higher prevalences of regular smoking. All of the following factors grouped under the term of family rapport were statistically associated with increased prevalence of regular smoking among students: low frequency of meals with the mother or responsible adult during the week, having parents or responsible adults who did not know what the student was doing most of the time and the perception that the parents would condone or tolerate student smoking (table 2).

Table 1 Prevalence of regular smoking* according to sociodemographic characteristics among school adolescents in 26 Brazilian state capitals and the Federal District

\begin{tabular}{|c|c|c|c|}
\hline $\begin{array}{l}\text { Socio-demographic } \\
\text { characteristics }\end{array}$ & $\begin{array}{l}\text { Prevalence } \\
\%(95 \% \text { CI) }\end{array}$ & OR $(95 \% \mathrm{CI})$ & p Value \\
\hline \multicolumn{4}{|l|}{ Sex } \\
\hline Male & $6.4(5.9$ to 6.9$)$ & 1.00 & \multirow[t]{2}{*}{0.789} \\
\hline Female & $6.3(5.7$ to 6.9$)$ & $0.98(0.86$ to 1.12$)$ & \\
\hline \multicolumn{4}{|l|}{ Age (years) } \\
\hline$<13$ & $3.5(2.9$ to 4.2$)$ & 1.00 & \multirow[t]{4}{*}{$<0.001$} \\
\hline 14 & $4.8(0.4$ to 0.5$)$ & $1.40(1.15$ to 1.71$)$ & \\
\hline 15 & 9.7 (8.7 to 10.7$)$ & $2.99(2.37$ to 3.76$)$ & \\
\hline $16+$ & $14.4(12.9$ to 16.0$)$ & 4.69 (3.76 to 5.85$)$ & \\
\hline \multicolumn{4}{|l|}{ Ethnic group/colour } \\
\hline White & 6.3 (5.7 to 6.9$)$ & 1.00 & \multirow[t]{5}{*}{0.101} \\
\hline Black & 7.2 (6.2 to 8.2$)$ & $1.16(0.97$ to 1.38$)$ & \\
\hline Brown & $6.0(5.4$ to 6.6$)$ & $0.95(0.83$ to 1.08$)$ & \\
\hline Yellow & $6.1(4.5$ to 6.6$)$ & $0.97(0.70$ to 1.35$)$ & \\
\hline Indigenous & $7.7(6.3$ to 9.3$)$ & $1.25(1.01$ to 1.54$)$ & \\
\hline \multicolumn{4}{|l|}{ Education of the mother } \\
\hline Graduate & 5.6 (4.8 to 6.6$)$ & 1.00 & \multirow[t]{6}{*}{0.001} \\
\hline $\begin{array}{l}\text { Incomplete undergraduate/ } \\
\text { complete middle school }\end{array}$ & $6.0(5.3$ to 6.7$)$ & $1.07(0.88$ to 1.30$)$ & \\
\hline $\begin{array}{l}\text { Incomplete middle school/ } \\
\text { complete primary education }\end{array}$ & 6.7 (5.7 to 7.8$)$ & $1.21(0.97$ to 1.50$)$ & \\
\hline Incomplete primary education & 6.7 (5.9 to 7.5$)$ & $1.20(0.98$ to 1.48$)$ & \\
\hline No schooling & 10.4 (8.3 to 10.1$)$ & $1.96(1.46$ to 2.65$)$ & \\
\hline Can't inform & $5.9(5.0$ to 7.0$)$ & $1.05(0.83$ to 1.34$)$ & \\
\hline \multicolumn{4}{|l|}{ Index of household assets } \\
\hline First tertile (lowest) & $6.3(5.7$ to 7.0$)$ & 1.00 & \multirow[t]{3}{*}{0.735} \\
\hline Second tertile & $6.1(5.5$ to 6.7$)$ & $0.96(0.83$ to 1.12$)$ & \\
\hline Third tertile (highest) & $6.4(5.7$ to 7.2$)$ & $1.02(0.87$ to 1.19$)$ & \\
\hline
\end{tabular}

Source: National Adolescent School-based Health Survey (PeNSE, 2009).

${ }^{*}$ Report of having smoked cigarettes at least once in the past 30 days preceding the questionnaire.
Table 2 Prevalence of regular smoking* according to school context household context and family rapport among school adolescents in 26 Brazilian state capitals and the Federal District

\begin{tabular}{|c|c|c|}
\hline & Prevalence \% (95\% CI) & p Value \\
\hline \multicolumn{3}{|l|}{ School context } \\
\hline \multicolumn{3}{|l|}{ Administrative domain } \\
\hline Public & $6.6(6.1$ to 71$)$ & 0.001 \\
\hline Private & $5.3(4.6$ to 6.1$)$ & \\
\hline \multicolumn{3}{|c|}{ Perception of access to cigarette purchase inside the school } \\
\hline No & $7.1(6.5$ to 7.7$)$ & $<0.001$ \\
\hline Yes & $14.9(13.5$ to 16.4$)$ & \\
\hline Not aware & $3.7(3.3$ to 4.1$)$ & \\
\hline \multicolumn{3}{|c|}{ Skipped classes without parental permission in the past 30 days } \\
\hline Never & $4.3(3.9$ to 4.6$)$ & $<0.001$ \\
\hline 1 or 2 days & $11.7(10.4$ to 13.3$)$ & \\
\hline 3 or more days & $23.8(21.1$ to 26.6$)$ & \\
\hline \multicolumn{3}{|l|}{ Report bullying } \\
\hline Never & $6.1(5.6$ to 6.7$)$ & 0.962 \\
\hline Rarely/sometimes & $6.2(5.5$ to 6.9$)$ & \\
\hline Most of the time/always & $6.2(4.3$ to 8.9$)$ & \\
\hline \multicolumn{3}{|l|}{ Household context } \\
\hline \multicolumn{3}{|l|}{ Family composition } \\
\hline Lives with father and mother & $4.8(4.4$ to 5.3$)$ & $<0.001$ \\
\hline Lives with mother & $8.0(7.2$ to 9.0$)$ & \\
\hline Lives with father & $9.2(7.4$ to 11.3$)$ & \\
\hline Doesn't live with father or mother & $9.6(8.0$ to 11.5$)$ & \\
\hline \multicolumn{3}{|l|}{ Parents or responsible adults smoke } \\
\hline None of them smoke & $4.8(4.4$ to 5.2$)$ & $<0.001$ \\
\hline One of them smokes & $11.3(9.5$ to 13.3$)$ & \\
\hline Both smoke & $8.9(7.9$ to 10.1$)$ & \\
\hline \multicolumn{3}{|c|}{ Other people smoked at home in the past 7 days } \\
\hline None & 4.5 (4.1 to 5.0$)$ & $<0.001$ \\
\hline $1-2$ days & 7.7 (6.3 to 9.2$)$ & \\
\hline $3-6$ days & $9.3(7.6$ to 11.2$)$ & \\
\hline Every day & $10.8(9.5$ to 12.2$)$ & \\
\hline \multicolumn{3}{|l|}{ Family rapport } \\
\hline \multicolumn{3}{|l|}{ Meals with mother or responsible adult } \\
\hline Every day & $5.2(4.7$ to 5.7$)$ & $<0.001$ \\
\hline At least on 1 day & $6.1(5.4$ to 6.9$)$ & \\
\hline Rarely & $7.5(6.4$ to 8.7$)$ & \\
\hline Never & $10.9(9.5$ to 12.4$)$ & \\
\hline \multicolumn{3}{|c|}{ Parents knew what child was doing in the past 30 days } \\
\hline Always/most of the time & $4.2(3.7$ to 4.7$)$ & $<0.001$ \\
\hline Sometimes/rarely/never & $8.8(8.2$ to 9.5$)$ & \\
\hline \multicolumn{3}{|c|}{ Perception of the parents' reaction if they smoked cigarettes } \\
\hline Would care a lot & $5.2(4.8$ to 5.6$)$ & $<0.001$ \\
\hline Would care little & $25.7(22.1$ to 29.6$)$ & \\
\hline Would not care & $29.4(23.8$ to 35.7$)$ & \\
\hline Don't know & $9.9(8.0$ to 11.4$)$ & \\
\hline
\end{tabular}

Source: National Adolescent School-based Health Survey (PeNSE, 2009).

${ }^{*}$ Report of having smoked cigarettes at least once in the past 30 days preceding the questionnaire.

In the multivariate analysis of the socio-demographic characteristics only the following remained associated with regular smoking: age ( 14 years: $O R=1.40,95 \%$ CI 1.15 to $1.69 ; 15$ years: $\mathrm{OR}=3.01,95 \%$ CI 2.40 to $3.79 ; 16$ years or above: $\mathrm{OR}=4.69,95 \%$ CI 3.78 to 5.81 ) and ethnic group/colour: dark $(\mathrm{OR}=0.84 ; 95 \%$ CI 0.75 to 0.96 ). The educational level of the mother was not statistically associated with regular smoking.

The results of the multivariate analysis after the adjustment by the variables included in the same block and age are presented in table 3. In the school context, reporting the possibility of purchasing cigarettes at school and skipping of classes without the permission of the parents or responsible adults remained independently associated with regular smoking. But the 
Table 3 Factors associated with regular smoking among school adolescents in 26 Brazilian state capitals and the Federal District in each of the contexts analysed (school, home and family rapport), before and after adjustment for the variables included in the same context and age

Crude OR (95\% Cl) Adj. OR* $(95 \% \mathrm{Cl})$

\begin{tabular}{|c|c|c|}
\hline \multicolumn{3}{|l|}{ School context } \\
\hline \multicolumn{3}{|l|}{ Administrative domain } \\
\hline Public & 1.00 & 1.00 \\
\hline Private & $0.80(0.67$ to 0.95$)$ & $1.22(1.01$ to 1.46$)$ \\
\hline \multicolumn{3}{|c|}{ Perception of access to cigarette purchase inside the school } \\
\hline No & 1.00 & 1.00 \\
\hline Yes & $2.29(2.00$ to 2.63$)$ & 1.79 (1.53 to 2.08$)$ \\
\hline Not aware & $0.50(0.44$ to 0.58$)$ & 0.51 (0.44 to 0.58$)$ \\
\hline \multicolumn{3}{|c|}{ Skipped classes without parental permission in the past 30 days } \\
\hline Never & 1.00 & 1.00 \\
\hline 1 or 2 days & $3.00(2.54$ to 3.54$)$ & 2.49 (2.09 to 2.97$)$ \\
\hline 3 or more days & $7.02(6.00$ to 8.21$)$ & 5.05 (4.31 to 5.92$)$ \\
\hline \multicolumn{3}{|l|}{ Household context } \\
\hline \multicolumn{3}{|l|}{ Family composition } \\
\hline Lives with father and mother & 1.00 & 1.00 \\
\hline Lives with mother & $1.71(1.48$ to 1.98$)$ & $1.51(1.30$ to 1.75$)$ \\
\hline Lives with father & 1.99 (1.53 to 2.58$)$ & $1.72(1.31$ to 2.26$)$ \\
\hline Doesn't live with father or mother & 2.09 (1.71 to 2.55$)$ & 1.65 (1.33 to 2.05$)$ \\
\hline \multicolumn{3}{|l|}{ Parents or responsible adults smoke } \\
\hline None of them smoke & 1.00 & 1.00 \\
\hline One of them smokes & $2.54(2.09$ to 3.10$)$ & 1.38 (1.08 to 1.77$)$ \\
\hline Both smoke & $1.96(1.68$ to 2.30$)$ & $1.17(0.95$ to 1.45$)$ \\
\hline \multicolumn{3}{|c|}{ Other people smoked at home in the past 7 days } \\
\hline None & 1.00 & 1.00 \\
\hline $1-2$ days & $1.75(1.39$ to 2.18$)$ & 1.49 (1.14 to 1.94$)$ \\
\hline $3-6$ days & 2.14 (1.73 to 2.66$)$ & 1.80 (1.39 to 2.33$)$ \\
\hline Every day & $2.54(2.17$ to 2.98$)$ & 2.04 (1.64 to 2.53$)$ \\
\hline \multicolumn{3}{|l|}{ Family rapport } \\
\hline \multicolumn{3}{|l|}{ Meals with mother or responsible adult } \\
\hline Every day & 1.00 & 1.00 \\
\hline At least on 1 day & $1.20(1.04$ to 1.38$)$ & $1.12(0.97$ to 1.30$)$ \\
\hline Rarely & $1.48(1.22$ to 1.80$)$ & $1.20(1.00$ to 1.45$)$ \\
\hline Never & $2.24(1.89$ to 2.65$)$ & 1.56 (1.30 to 1.88$)$ \\
\hline \multicolumn{3}{|c|}{ Parents knew what child was doing in the past 30 days } \\
\hline Always/most of the time & 1.00 & 1.00 \\
\hline Sometimes/rarely/never & 2.21 (1.93 to 2.52$)$ & 1.68 (1.45 to 1.96$)$ \\
\hline \multicolumn{3}{|c|}{ Perception of the parents' reaction if they smoked cigarettes } \\
\hline Would care a lot & 1.00 & 1.00 \\
\hline Would care little & 6.33 (5.11 to 7.86 ) & 4.97 (3.99 to 6.19$)$ \\
\hline Would not care & 7.64 (5.64 to 10.36$)$ & 5.25 (3.78 to 7.32$)$ \\
\hline Don't know & 1.94 (1.56 to 2.40$)$ & 1.45 (1.17 to 1.82 ) \\
\hline
\end{tabular}

Source: National Adolescent School-based Health Survey (PeNSE, 2009).

${ }^{*} \mathrm{OR}$ adjusted by variables included in the same block plus age.

direction of the association between school domain and smoking changed, with studying at a private school being associated with a higher risk of regular smoking.

In the household context, living with one or none of the parents, parental smoking and exposure to other people smoking at home all remained independently associated with smoking. With regard to the indicators of family rapport, low frequency of meals with the mother (or equivalent), the fact that parents did not know what the adolescent was doing most of the time in the past 30 days and the perception that parents would worry only a little or not at all if the student smoked, have also remained independently associated with smoking.

\section{DISCUSSION}

The results show that one out of four high school students had already experimented with cigarettes and that half of those students were 12 years old or younger when they tried cigarettes for the first time. We also identified important associations between factors present in the school, household and family contexts and regular smoking.

The proportion of high school students who had experimented with tobacco identified in this study, although high, was lower than the average reported for students from 35 European countries with ages ranging from 13 to 15 years $(43 \%$ and $62 \%$, respectively $)^{16}$. A recent survey in India also found a higher prevalence of experimentation with smoking among 6th grade students with the mean age of 13 years $(32 \%) .{ }^{17}$ Differing from the WHO European survey, we did not find any statistical difference in the prevalence of cigarette experimentation between sexes. Among European students the prevalence was higher for boys at the age of 11 years and older and for girls at the age of 15 years and older, suggesting that boys experimented with cigarettes earlier than girls. ${ }^{16}$

Experimentation with smoking is an important problem and seems to be associated with tobacco addiction. Gilpin et al estimated that about half of the adolescents who have already tried cigarettes-as compared with only $9 \%$ of those who have never smoked-are at increased risk of becoming smokers. ${ }^{18}$ So far, the influence of the age of experimentation on future smoking is not clear. Breslau et al have found that individuals who started smoking before the age of 14 years did not have a higher probability of smoking on a daily basis when compared with those who started smoking after this age. ${ }^{19}$ However, another study, after considering the confounding factors, has found that the probability of quitting is significantly higher in people who start smoking at the age of 14 years or older, compared with those who start smoking at the age of 13 years or younger. ${ }^{20}$

The prevalence of the regular use of cigarettes did not differ between boys and girls and was lower than the reported use in several western countries using the same definition. For instance, the Global Youth Tobacco Survey 2000-2007, under the coordination of the Centers for Disease Control, which includes a sample of high school students between the age of 13 and 15 years in 151 countries, reported an overall prevalence of regular use of tobacco in $9.5 \%$ of the sample, ranging from $4.9 \%$, in region of the Americas, to 19\% in the European region, with no statistical difference between the sexes. ${ }^{21}$

In the present survey, the prevalence of regular smoking was about five times lower than the rate, based on the same definition, found in Chile and half of those reported by other Brazilian studies. ${ }^{22}$ In comparison with other Brazilian data, the present results suggest a fall in the prevalence of smoking among high school students. This reduction is in agreement with the decreasing trend of smoking among adults in the country, as a result of anti-smoking initiatives which have been taken up in Brazil since the 1990s. ${ }^{23}$

Regular smoking practice in adolescence is a big worry because of its association to daily smoking and nicotine dependence. It is estimated that three out of four adolescents who smoke will continue to do so when becoming adults. ${ }^{24}$ A recent systematic review has shown that the frequency of relapses in trials to quit smoking is high among adolescents who smoked regularly, including younger ones and those who weren't daily smokers. ${ }^{25}$ Apart from the risks related to the course of daily smoking during adulthood, regular smoking in adolescence is associated with a poor health condition, including reduction of lung functions, increase of asthma attacks and bronchitis and reduction of physical fitness. ${ }^{26}$

Among the socio-demographic characteristics analysed, other than ethnic group/skin colour, age was the only factor positively 
and independently associated with regular smoking among Brazilian high school children. This finding is equivalent to the majority of studies carried out worldwide. A recent study in the country also agrees with our results of no statistical difference in the prevalence of smoking between sexes. ${ }^{27}$ Regarding the social indicators, neither the educational level of the mother nor the index of assets showed an association with regular smoking in the present analysis. A prospective study of 877 Canadian students with an average age of 12.7 years did not identify the influence of parents' educational level over the risk of trying cigarettes or of progression to daily smoking among the students who had experimented with cigarettes. The results of the studies which investigated the influence of socio-economic factors over the prevalence of regular smoking are actually inconsistent, but the majority of them do not report any statistical association. ${ }^{28}$ Such findings may be related to an attenuation of parental socio-economic factors on child's health during adolescence. Several studies, including one in Brazil, corroborate this finding, but there is no consensual explanation for such observations. ${ }^{29}$ With regard to student smoking, a recent study based on 97721 school children from 33 European countries, did not find a socio-economic pattern. Their results show weak associations which were present only in few of the countries studied. ${ }^{30}$

In the school context, we found an independent association between regular smoking and all the analysed variables, except for bullying in the past 30 days. The access to the purchase of cigarettes inside school and skipping of classes without the knowledge of the parents were all associated with a higher prevalence of smoking. These results are consistent with the great majority of studies which analysed similar variables. In the univariate analysis, attending public high schools was related to higher prevalence of regular smoking, similarly to what was found among high school students in Argentina and India. ${ }^{17} 31$ However, this association reversed in the multivariate to higher prevalence of regular smoking among private school children. This change suggests that the positive association between studying at public school and regular smoking found in the univariate analysis was due to the confounding effect of age, as 9 th grade pupils in these schools are younger than in the public ones $(p<0.001)$. For instance, while in private schools $86.8 \%$ of the children were $13-14$ years old, in public schools $66.6 \%$ were in this age range. Also, a stratified analysis of private and public schools confirm the highly significant and positive association of age and the other school variables with regular smoking in both administrative domains. If we consider studying at private schools as an indicator of affluence, then this result suggests an inverse association between socio-economic condition and smoking in adolescence. This finding reinforces the already reported inconsistencies in the association between socioeconomic factors and smoking in adolescence. ${ }^{30}$

The access to purchasing cigarettes is one of the most studied variables and is clearly associated with smoking. ${ }^{32} 33$ The association between regular smoking and absence from school without the knowledge of the parents may be understood in the context of a general tendency of a cluster of risk behaviours, which are in turn associated with a worse school performance. ${ }^{34}$ This can, however, also indicate a worse engagement in school or a lower satisfaction with school, more common among students who smoke regularly. ${ }^{35}$ Thus, it is important to consider the school context as an integrated issue and not as a sum of individual factors. The school is not only a place where the child spends most of his or her time and makes friends, but is also a complex social and cultural context which interacts with and influences the students' behaviour. ${ }^{36}$ Schools are a privileged space for the implementation of public policies directed towards individuals in this age group, especially health promoting policies.

The family is possibly the context in which the social behaviours and attitudes are formed and there are evidences that it is the most important context for the emergence of most concepts related to health during lifetime. ${ }^{16}$ There are consistent evidences that the composition, values and family relations have an important impact on the exposure to smoking during adolescence. ${ }^{1}$ Support from parents and their close monitoring of their child have been found to be negatively associated with various risk behaviour, including smoking. ${ }^{37}$ It also appears that parents' involvement and expectations can act as protective factors against the development of risk behaviours. ${ }^{35}$

Our results confirm such evidences. In the multivariate analysis by blocks of affinity, all variables related to the family composition and relationship, as well as those related to the parents' behaviour and their judgement, have remained independently associated with regular smoking among high school students. The exposure to cigarettes at home and smoking parents are clearly relevant to experimentation and continued smoking among students. The family support is a protective factor against experimentation with cigarettes, in the same way as the reaction of the parents to smoking. A recent study among Israeli school students, using structural equation analysis, reinforced that parental support and monitoring is protective of student's health and risk behaviours. ${ }^{38}$

Even though the school-based survey-PeNSE-is the biggest of its kind in Brazil, with over 60000 participants, it does not represent the whole country as it was carried out solely in the state's capitals and the Federal District. Thus, the estimated average prevalence in this study does not rigorously represent the school population of the 9th grade attending primary schools in the country. It is possible that the distribution of the students' characteristics and the prevalence of smoking found are somewhat different in the cities from the interior regions of the states, especially in the small towns. Yet, as the great majority of our population resides in medium and large municipalities, it is possible that the examined reality may very well reflect the great majority of high school students in the 9th grade of schools in the country.

The analysis performed here was not intended to identify causal relationships as the data are cross-sectional. The goal of the analysis was to identify the factors which help in the understanding of smoking habits among youngsters as multifactorial and contextual phenomena. For this reason, we have opted to gather the variables by thematic affinity and carry out the multivariate analysis inside each block while also adjusting to age. It is possible that some variables of different contexts are correlated and that some of them cease to be statistically significant in a multivariate analysis including all of the variable blocks. However, such procedures would conceal contextual indicators which help to better understand the problem and thus direct public policies to prevent smoking and promote youngsters' health. This is essential, as observational studies show that public smoking control policies can have a positive impact on the reduction of smoking prevalence among adolescents of all social classes. $^{39} 40$

This study has used a set of indicators in the survey to analyse the individual and contextual factors associated with smoking among high school students. These factors were measured by self-applied interviews and may contain measurement errors because of under-reports or different levels of difficulty in 


\section{What is already known on this subject}

- The exposure to smoking during adolescence has various important implications for the well-being and health of the adolescent.

- The use of tobacco during adolescence is also associated with the use during adulthood.

- The use of tobacco during adolescence is, in most part, culturally and socially determined.

\section{What this study adds}

- The educational level of the mother is not statistically associated with regular smoking among Brazilian school teenagers.

- The possibility of purchasing cigarettes at school and exposure to parental or other householders' smoking increase the chances of smoking among Brazilian adolescents.

- Parents' negative reactions towards adolescent smoking and having meals with mothers seem to reduce smoking during adolescence.

understanding the questions. The survey was also preceded by pilot studies which tested the comprehension of the questionnaire. The choice of students from the 9 th grade aimed at minimising the influence of possible differences in reading abilities between the students included in the sample. As for the potential of under-reporting smoking, it is possible, as confirmed by a study carried out in Southern Brazil. ${ }^{41}$ However, this method is the only one that allows carrying out research studies on such a large scale as this survey. Furthermore, we believe that the use of the PDA created an environment of greater privacy for answering the questionnaire, which should increase the reliability of the answers.

\section{CONCLUSION}

Our results reinforce the importance of considering smoking during adolescence as a multifactorial and socially determined phenomenon. Factors in the school environment, household context and family relationship contribute to explain the exposure to smoking during adolescence. Public health policies aimed at preventing smoking and health promotion during adolescence should consider that improvements in the child's environments will certainly bring benefits to various aspects of the students' well-being and health.

Acknowledgements SMB received a research grant from CNPq (Brazilian Ministry of Science and Technology) and LG from CAPES (Brazilian Ministry of Education).

Funding Brazilian Ministry of Health.

Competing interests None.

Ethics approval This study was conducted with the approval of the Brazilian National Ethics Committee.

Provenance and peer review Not commissioned; externally peer reviewed.

\section{REFERENCES}

1. Turner L, Mermelstein R, Flay B. Individual and contextual influences on adolescent smoking. Ann N Y Acad Sci 2004;1021:175-97.
2. DiFranza JR, Rigotti NA, McNeill $A D$, et al. Initial symptoms of nicotine dependence in adolescents. Tob Control 2000;9:313-19.

3. Doubeni CA, Reed G, Difranza JR. Early course of nicotine dependence in adolescent smokers. Pediatrics 2010:125:1127-33.

4. Colby SM, Tiffany ST, Shiffman S, et al. Are adolescent smokers dependent on nicotine? A review of the evidence. Drug Alcohol Depend 2000;59(Suppl 1):S83-95.

5. Brook DW, Brook JS, Zhang C, et al. Developmental trajectories of cigarette smoking from adolescence to the early thirties: personality and behavioral risk factors. Nicotine Tob Res 2008;10:1283-91.

6. Peto R, Darby S, Deo H, et al. Smoking, smoking cessation, and lung cancer in the UK since 1950: combination of national statistics with two case-control studies. BM 2000;321:323-9.

7. Kestilä L, Martelin T, Rahkonen 0 , et al. The contribution of childhood circumstances, current circumstances and health behaviour to educational health differences in early adulthood. BMC Public Health 2009:9:164.

8. Koivusilta L, Rimpelä A, Vikat A. Health behaviours and health in adolescence as predictors of educational level in adulthood: a follow-up study from Finland. Soc Sci Med 2003:57:577-93.

9. Kobus K. Peers and adolescent smoking. Addiction 2003;98(Suppl 1):37-55

10. Smetana JG, Campione-Barr N, Metzger A. Adolescent development in interpersonal and societal contexts. Annu Rev Psychol 2006;57:255-84.

11. DiFranza JR, Savageau JA, Fletcher KE. Enforcement of underage sales laws as a predictor of daily smoking among adolescents: a national study. BMC Public Health 2009;9:107.

12. Wilkinson AV, Shete S, Prokhorov AV. The moderating role of parental smoking on their children's attitudes toward smoking among a predominantly minority sample: a cross-sectional analysis. Subst Abuse Treat Prev Policy 2008;3:18.

13. Farrelly MC, Davis KC, Haviland ML, et al. Evidence of a dose-response relationship between "truth" antismoking ads and youth smoking prevalence. Am J Public Health 2005:95:425-31

14. Malta DC, Sardinha LMV, Mendes I, et al. Vigilância de fatores de risco e proteção de doenças crônicas não transmissíveis em adolescentes no Brasil [Prevalence of risk health behavior among adolescents: results from the 2009 National Adolescent School-based Health Survey (PeNSE)]. Cien Saude Colet 2010;15(Suppl 2):3009-19.

15. Szwarcwald CL, Souza-Júnior PR, Esteves MA, et al. Socio-demographic determinants of self-rated health in Brazil. Cad Saúde Pública 2005;21 (Suppl):54-64.

16. WHO. Young people's health in context. In: Currie C, Roberts C, Morgan A, et al, eds Health Behaviour in School-aged Children (HBSC) Study: International Report From the 2001/2002 Survey. Copenhagen: WHO Regional Office for Europe, 2004

17. Reddy KS, Perry CL, Stigler MH, et al. Differences in tobacco use among young people in urban India by sex, socioeconomic status, age, and school grade: assessment of baseline survey data. Lancet 2006;367:589-94.

18. Gilpin EA, White VM, Pierce JP. What fraction of young adults are at risk for future smoking, and who are they? Nicotine Tob Res 2005:7:747-59.

19. Breslau N, Fenn N, Peterson EL. Early smoking initiation and nicotine dependence in a cohort of young adults. Drug Alcohol Depend 1993;33:129-37.

20. Breslau N, Peterson EL. Smoking cessation in young adults: age at initiation of cigarette smoking and other suspected influences. Am J Public Health 1996:86:214-20.

21. Warren CW, Jones NR, Peruga A, et al. Global Youth Tobacco Surveillance, 2000-2007. MMWR Surveill Summ 2008;57:1-28.

22. Malcon MC, Menezes AM, Maia Mde F, et al. Prevalence of and risk factors for cigarette smoking among adolescents in South America: a systematic literature review. Rev Panam Salud Publica 2003;13:222-8.

23. Monteiro CA, Cavalcante TM, Moura EC, et al. Population-based evidence of a strong decline in the prevalence of smokers in Brazil (1989-2003). Bull World Health Organ 2007:85:527-34

24. Moolchan ET, Ernst M, Henningfield JE. A review of tobacco smoking in adolescents: treatment implications. J Am Acad Child Adolesc Psychiatry 2000:39:682-93.

25. Bancej C, O'Loughlin J, Platt RW, et al. Smoking cessation attempts among adolescent smokers: a systematic review of prevalence studies. Tob Control 2007; 16:e8.

26. Henderson AJ. The effects of tobacco smoke exposure on respiratory health in school-aged children. Paediatr Respir Rev 2008:9:21-7.

27. Hallal AL, Gotlieb SL, Almeida LM, et al. Prevalence and risk factors associated with smoking among school children, Southern Brazil. Rev Saude Publica 2009:43:779-88

28. O'Loughlin J, Karp I, Koulis T, et al. Determinants of first puff and daily cigarette smoking in adolescents. Am J Epidemiol 2009;170:585-97.

29. Barreto SM, Giatti L, Hernaez AM. Contextual and family factors associated with negative assessment of children's health. Eur J Public Health Published Online First: 6 June 2010. doi:10.1093/eurpub/ckq071.

30. Richter M, Erhart M, Vereecken CA, et al. The role of behavioural factors in explaining socio-economic differences in adolescent health: a multilevel study in 33 countries. Soc Sci Med 2009;69:396-403.

31. Bolzán A, Peleteiro R. Tabaquismo durante la adolescencia temprana. Estudio em escolares argentinos. J Pediatr (Rio j) 2003;79:461-6.

32. Johnston LD, O'Malley PM, Terry-McElrath YM. Methods, locations, and ease of cigarette access for American youth, 1997-2002. Am J Prev Med 2004;27:267-76 
33. Leatherdale ST, Strath JM. Tobacco retailer density surrounding schools and cigarette access behaviors among underage smoking students. Ann Behav Med 2007:33:105-11.

34. Leatherdale ST, Hammond D, Ahmed R. Alcohol, marijuana, and tobacco use patterns among youth in Canada. Cancer Causes Control 2008;19:361-9.

35. Rasmussen M, Damsgaard MT, Holstein BE, et al. School connectedness and daily smoking among boys and girls: the influence of parental smoking norms. Eur J Public Health 2005;15:466-75.

36. Piontek D, Buehler A, Rudolph U, et al. Social contexts in adolescent smoking: does school policy matter? Health Educ Res 2008;23:1029-38.

37. Warren CW, Jones NR, Eriksen MP, et al. Patterns of global tobacco use in young people and implications for future chronic disease burden in adults. Lancet 2006;367:749-53
38. Walsh SD, Harel-Fisch Y, Fogel-Grinvald H. Parents, teachers and peer relations as predictors of risk behaviors and mental well-being among immigrant and Israeli born adolescents. Soc Sci Med 2007;70:976-84.

39. White VM, Hayman J, Hill DJ. Can population-based tobacco-control policies change smoking behaviors of adolescents from all socio-economic groups? Findings from Australia: 1987-2005. Cancer Causes Control 2008;19:631-40.

40. Botello-Harbaum MT, Haynie DL, lannotti RJ, et al. Tobacco control policy and adolescent cigarette smoking status in the United States. Nicotine Tob Res 2009;11:875-85

41. Malcon MC, Menezes AM, Assunção MC, et al. Agreement between self-reported smoking and cotinine concentration in adolescents: a validation study in Brazil. J Adolesc Health 2008:43:226-30. 